\title{
Visibilización de la comunidad de vendedores ambulantes y estacionarios de la ciudad de Palmira (impacto socioeconómico)
}

\author{
Martha Lucía Fuertes D. ${ }^{1}$ \\ Julio Cesar Montoya R. ${ }^{2}$ \\ Marilu Avendaño A. ${ }^{3}$
}

\section{RESUMEN}

El tema de los "vendedores ambulantes" configura el objeto de estudio de la actual investigación; ejercicio académico, cuya finalidad central fue caracterizar para el municipio de Palmira (Valle del Cauca), el manejo, la contextualización y el "día a día" de esta vasta comunidad de este tipo de comerciantes informales para determinar los factores incidentes del subdesarrollo comunitario.

La primera parte de esta monografía, concierne a la cronología de esta población de seudocomerciantes, el recuento histórico de su surgimiento, cifras, estadísticas, y su advenimiento y consolidación como gremio comercial alternativo en el municipio de Palmira. Subsecuentemente, la segunda parte compete al análisis de los diferentes puntos de vista sobre esta comunidad, incluyendo la opinión de ellos mismos. Se tuvo en cuenta en el trabajo de campo, la opinión de miembros de este grupo por considerarse un tema de connotaciones sociales.

La parte final, describe las diferentes actividades relacionadas con el manejo que se le ha dado a este gremio, y los diferentes programas y proyectos que a mediano o largo plazo se tiene para con esta comunidad.

Palabras clave: vendedores ambulantes, economía informal, comercio, subdesarrollo

\footnotetext{
${ }^{1}$ Contadora Pública, Especialista en Finanzas, Maestría en Administración,docente Universidad Nacional Abierta y a Distancia - UNAD. martha.fuertes@unad.edu.co

2 Administrador de Empresas, Especialista en Pedagogía para el Desarrollo del Aprendizaje Autónomo, Maestría en Administración de Empresas. Docente de la Universidad Nacional Abierta y a Distancia UNAD.julio.montoya@unad.edu.co

${ }^{3}$ Administradora de Empresas, Especialista Gestión de Proyectos y en Educación Superior a Distancia, Magíster en Educación. marilu.avendano@unad.edu.co
} 


\section{Introducción}

Las ideas de negocio de índole informal, proliferan hoy día a lo largo y ancho de la geografía colombiana, independientemente de la causa que da origen a este preocupante fenómeno, el hecho es que tanto vendedores ambulantes, como estacionarios confluyen masivamente en las partes céntricas de la ciudad, luchando por su diario sustento.

Las cifras nacionales hablan de más de 60 mil vendedores ambulantes, sólo en Bogotá y por lo menos 200 mil en todo el país. Su crecimiento se registra entre un 50 y 60 por ciento en los últimos dos años.

El tema de objeto de estudio de la presente monografía, es precisamente esta comunidad, y la pretensión de esta investigación es visibilizar este fenómeno socio económico en el contexto palmirano

\section{Génesis de los actores de esta actividad comercial (Venta ambulante)}

Las personas que realizan esta actividad reciben muchos nombres ya sea como vendedores directos, o bien, representantes de ventas, ejecutivos de cuenta, consultores de ventas, ingenieros de ventas, agentes, gerentes de distrito, representantes de desarrollo de cuenta, vendedores ambulantes, comerciantes, comerciantes ambulantes y caravanas, son parte de una antigua tradición que se originó en una necesidad básica del hombre de intercambiar artículos y de comunicarse. Timbres, catálogos y órdenes de compra estaban a siglos de distancia de aquel vendedor directo que confiaba en sus instintos y sentido común para ganarse la vida a través de la venta. (Posada, Dávila Rincón, \& Castro Estrada, 2008)

\section{El poder Comunicativo de los vendedores ambulantes}

Los vendedores ambulantes despliegan lo que, según palabras de Goffman, (1970) , es denominado una línea; es decir, un esquema de actos verbales y no verbales por medio de los cuales expresan su enfoque de la situación, y -por medio de este su evaluación de los participantes, en especial de sí mismos.

La línea de la que habla Goffman, en este contexto específico de venta, requiere que estos actores sociales estén en posesión y completo dominio tanto de herramientas lingüísticas (conocimientos gramaticales) como del uso apropiado de ellas. Esto es concebido por (Hymes, 1972) y los etnógrafos de la comunicación como la "competencia comunicativa". Este conocimiento no solo incluye reglas de comunicación (lingüísticas y sociolingüísticas) y reglas compartidas de interacción, sino también "reglas culturales que forman la base del contexto y contenido de los sucesos comunicativos y de los procesos de interacción" (Saville-Troike, 2005). De este modo, en una situación concreta, los hablantes sabrán desplegar, de forma apropiada, los usos lingüísticos necesarios para lograr la finalidad perseguida; en el caso de los 
vendedores ambulantes latinoamericanos, harán uso de los giros idiomáticos y la propia jerga local.

"La venta personal se basa en una comunicación personal ya que va de una persona el vendedor a otra persona el cliente potencial o comprador, (Abad, 1997). "Nosotros consideramos a la venta personal como la forma más efectiva de vender un producto y de conseguir un cliente satisfecho con posibilidades de que pueda repetir la compra" (Werther \& Keith, 2000).

Estudios realizados a nivel internacional muestran que la forma más efectiva de cerrar una venta es con el método llamado "Cara a Cara" ya que en este el vendedor crea un vínculo con el comprador, y el cliente al mostrarle directamente el producto crea un sentido de pertenencia. (Serna, 2000)

Otros autores consideran que "las ventas personales son una comunicación directa de información, a diferencia de la comunicación indirecta e impersonal de la publicidad, las promociones de ventas y otras herramientas promocionales". (Stanton, Etzel, \& Walker, 2004). Esto significa que las ventas personales pueden ser más flexibles que las demás herramientas promocionales. Los vendedores pueden individualizar sus presentaciones para adecuarlas a las necesidades y comportamiento de cada cliente. Pueden ver las reacciones de los clientes a cierto esquema de ventas y hacer ajustes sobre la marcha.

Asimismo, las ventas personales pueden enfocarse en individuos o empresas que se sabe que son clientes posibles, si es que la organización hizo bien su trabajo al dividir en segmentos y nichos mercado. Como resultado, los esfuerzos empeñados son mínimos. En cambio, los mensajes de la publicidad muchas veces se desperdician en personas que en realidad no son clientes potenciales.

Otra ventaja de las ventas personales es que su objetivo es concretar una venta. La publicidad tiene un objetivo menos ambicioso y en general está destinada a llamar la atención, proveer información y despertar un deseo, pero rara vez incita una acción de compra o completa la transferencia de un título del vendedor al comprador. (Reid, 1990)

\section{Comercio Informal y el contexto latinoamericano}

A partir de la década de los ochenta, los países de América Latina han atravesado por un periodo de cambios económicos, políticos e institucionales que han configurado gran parte del panorama actual. En muchos casos, la restauración de los mecanismos del mercado ha llevado a disminuir la intervención del Estado en diversas esferas. Paralelamente, la baja de empleos y la agudización de la pobreza han deteriorado las condiciones de vida y hecho dela supervivencia una tarea difícil. Así, en muchos de estos países, incluido el nuestro, las migraciones y, con ellas, la búsqueda de nuevas oportunidades laborales y de ascenso social han configurado nuevas formas de trabajo, como es el caso del comercio informal o callejero (Veleda da Silva, 2003) (Veleda Da Silva 2003).

\section{Fases de la Investigación}


Fase 1: Contextualización cronológica del Objeto de Estudio

En esta fase inicial se llevó a cabo un recorrido cronológico de la aparición de esta informal actividad comercial como gremio masivo.

Fase 2: Identificación de las actividades comerciales inherentes a esta Comunidad

En esta segunda fase, se procedió a identificar los tipos, categorías de productos y vendedores, y modalidades de venta; lo que ofrecen, los insumos, lo que les cuesta la mercancía, los proveedores, la consecución de los recursos para la compra de insumo, lugares de ubicación de la venta, entre otros.

Fase 3: Análisis y discusión del Objeto de Estudio

La tercera fase correspondió al análisis y subjetividad relacionada con el tema, proveniente de las diferentes percepciones de los grupos de interés, para lo cual se utilizaron las técnicas e instrumentos escogidos para dicha finalidad (observación, entrevistas, cuestionarios, entre otros)

Fase 4: Relación de los programas actuales y futuros sobre el manejo de esta comunidad

En la fase final se hizo una relación de los diferentes programas públicos concernientes al manejo de esta comunidad, a corto, mediano y largo plazo.

\section{Identificación de las actividades comerciales informales inherentes a esta comunidad}

Caracterización de los vendedores y tipo de mercancía ofrecida

Para llevar a cabo este proceso se hizo un recorrido por la mayoría de barrios y localias del sector céntrico de la ciudad:

\begin{tabular}{|c|c|c|c|c|c|c|c|}
\hline $\begin{array}{l}\text { Que } \\
\text { comercializ } \\
\text { a }\end{array}$ & Quien lo hace & $\begin{array}{l}\text { En qué } \\
\text { jornada }\end{array}$ & $\begin{array}{l}\text { Genero del } \\
\text { vendedor }\end{array}$ & $\begin{array}{l}\text { Forma de } \\
\text { distribuci } \\
\text { ón }\end{array}$ & $\begin{array}{l}\text { Utensilios/he } \\
\text { rramientas/m } \\
\text { edios }\end{array}$ & $\begin{array}{l}\text { Forma de } \\
\text { promoción }\end{array}$ & Sector \\
\hline $\begin{array}{l}\text { Frutas } \\
\text { (chontaduro } \\
\text { s) }\end{array}$ & $\begin{array}{l}\text { Propietaria } \\
\text { /hijos o nietos }\end{array}$ & Mañana/tarde & Femenino & $\begin{array}{l}\text { Estacionari } \\
\text { a/Móvil }\end{array}$ & $\begin{array}{l}\text { Platón } \\
\text { metálico/Recip } \\
\text { iente plástico }\end{array}$ & Pregoneo & $\begin{array}{l}\text { Céntrico/p } \\
\text { eriferia }\end{array}$ \\
\hline Mazamorra & Propietario & Mañana/tarde & Masculino & Móvil & $\begin{array}{l}\text { Fondo } \\
\text { empotrado en } \\
\text { una cicla/moto }\end{array}$ & $\begin{array}{l}\text { Corneta/ } \\
\text { Pregoneo }\end{array}$ & $\begin{array}{l}\text { Periferia } \\
\text { /barrios }\end{array}$ \\
\hline $\begin{array}{l}\text { Avena/empa } \\
\text { nadas }\end{array}$ & $\begin{array}{l}\text { Vendedor } \\
\text { contratado }\end{array}$ & Mañana/Tarde & Femenino & $\begin{array}{l}\text { Estacionari } \\
0\end{array}$ & $\begin{array}{l}\text { Bidon con } \\
\text { sombrilla }\end{array}$ & $\begin{array}{l}\text { Paraguas } \\
\text { Ilamativo }\end{array}$ & $\begin{array}{l}\text { Periferia/Z } \\
\text { ona } \\
\text { céntrica/Pu } \\
\text { ntos de } \\
\text { sudor }\end{array}$ \\
\hline
\end{tabular}




\begin{tabular}{|c|c|c|c|c|c|c|c|}
\hline la basura & informal & & & $\begin{array}{l}\text { (tocando } \\
\text { de puerta } \\
\text { en puerta) }\end{array}$ & (pies) & & \\
\hline $\begin{array}{l}\text { Vendedores } \\
\text { de minutos }\end{array}$ & Propietario & $\begin{array}{l}\text { Mañana/tarde/ } \\
\text { noche }\end{array}$ & $\begin{array}{l}\text { Femenino/M } \\
\text { asculino }\end{array}$ & $\begin{array}{l}\text { Estacionari } \\
\text { o (salidas } \\
\text { de } \\
\text { establecimi } \\
\text { entos } \\
\text { grandes, } \\
\text { supermerc } \\
\text { ados, } \\
\text { clínicas, } \\
\text { bancos, } \\
\text { notarias, } \\
\text { etc) }\end{array}$ & $\begin{array}{l}\text { Silla, móviles, } \\
\text { butacos }\end{array}$ & $\begin{array}{l}\text { Letreros } \\
\text { fosforecente } \\
\text { s, pregoneo }\end{array}$ & $\begin{array}{l}\text { Periferia/B } \\
\text { arrios/Sect } \\
\text { or céntrico }\end{array}$ \\
\hline $\begin{array}{l}\text { Vendedores } \\
\text { de películas, } \\
\text { mp3 }\end{array}$ & $\begin{array}{l}\text { Cualquier } \\
\text { persona }\end{array}$ & $\begin{array}{l}\text { Mañana/tarde/ } \\
\text { eventualmente } \\
\text { por la noche }\end{array}$ & Masculino & $\begin{array}{l}\text { Móvil } \\
\text { (Puerta a } \\
\text { puerta/zon } \\
\text { a céntrica } \\
\text { /semáforos } \\
\text { ) }\end{array}$ & $\begin{array}{l}\text { Si con } \\
\text { estacionarios, } \\
\text { cajonero, } \\
\text { estera, tv, } \\
\text { dispositivo } \\
\text { mp4 }\end{array}$ & Pregoneo & $\begin{array}{l}\text { Céntrico/p } \\
\text { eriferia }\end{array}$ \\
\hline $\begin{array}{l}\text { Queso, } \\
\text { gelatina, } \\
\text { suspiros }\end{array}$ & $\begin{array}{l}\text { Cualquier } \\
\text { persona }\end{array}$ & Mañana/tarde & $\begin{array}{l}\text { Masculino/fe } \\
\text { menino }\end{array}$ & $\begin{array}{l}\text { Móvil (Por } \\
\text { las calles o } \\
\text { ubicados } \\
\text { en partes } \\
\text { estratégica } \\
\text { s) }\end{array}$ & $\begin{array}{l}\text { Bicicleta, } \\
\text { recipiente, } \\
\text { exhibidor }\end{array}$ & $\begin{array}{l}\text { Letreros, o } \\
\text { Pregoneo }\end{array}$ & $\begin{array}{l}\text { Periferia,/B } \\
\text { arrios }\end{array}$ \\
\hline $\begin{array}{l}\text { Cascos para } \\
\text { motos, } \\
\text { accesorios, } \\
\text { chalecos } \\
\text { reflectivos, } \\
\text { stickers }\end{array}$ & $\begin{array}{l}\text { Propietario/co } \\
\text { ntratados }\end{array}$ & Mañana/tarde & $\begin{array}{l}\text { Masculino/F } \\
\text { emenino }\end{array}$ & $\begin{array}{l}\text { Estacionari } \\
0\end{array}$ & $\begin{array}{l}\text { Locales, } \\
\text { escaparates, } \\
\text { para exhibir la } \\
\text { mercancía }\end{array}$ & $\begin{array}{l}\text { Avisos, } \\
\text { visualización }\end{array}$ & $\begin{array}{l}\text { Barrios } \\
\text { /Sector } \\
\text { céntrico, } \\
\text { sitios } \\
\text { estratégico } \\
\text { s }\end{array}$ \\
\hline $\begin{array}{l}\text { Venta de } \\
\text { helados, } \\
\text { productos de } \\
\text { cremería }\end{array}$ & Contratados & Mañana/tarde & $\begin{array}{l}\text { Masculino/fe } \\
\text { menino }\end{array}$ & $\begin{array}{l}\text { Móvil (Por } \\
\text { las calles o } \\
\text { ubicados } \\
\text { en "puntos } \\
\text { de sudor") }\end{array}$ & $\begin{array}{l}\text { Bicicleta, } \\
\text { moto, caja de } \\
\text { icopor }\end{array}$ & Pregoneo & $\begin{array}{l}\text { Barrios/Se } \\
\text { ctor } \\
\text { céntrico }\end{array}$ \\
\hline Artesanías & Contratados & Mañana/tarde & $\begin{array}{l}\text { Masculino/F } \\
\text { emenino }\end{array}$ & $\begin{array}{l}\text { Estacionari } \\
0\end{array}$ & $\begin{array}{l}\text { Estera, ropón } \\
\text { exhibidor en el } \\
\text { anden }\end{array}$ & $\begin{array}{l}\text { Visualizació } \\
\mathrm{n} \text {, la gente } \\
\text { sabe su } \\
\text { ubicación }\end{array}$ & $\begin{array}{l}\text { Céntrico, } \\
\text { parques } \\
\text { emblemáti } \\
\text { cos }\end{array}$ \\
\hline $\begin{array}{l}\text { Tinto/café } \\
\text { con leche }\end{array}$ & $\begin{array}{l}\text { Vendedores } \\
\text { informales }\end{array}$ & $\begin{array}{l}\text { Mañana/tarde/ } \\
\text { madrugada }\end{array}$ & $\begin{array}{l}\text { Femenino/ev } \\
\text { ntualmente } \\
\text { masculino }\end{array}$ & Móvil & $\begin{array}{l}\text { Cafeteras, } \\
\text { termos, vasos } \\
\text { desechables }\end{array}$ & Pregoneo & $\begin{array}{l}\text { Por las } \\
\text { calles, } \\
\text { sector } \\
\text { galería, } \\
\text { sector } \\
\text { industrial }\end{array}$ \\
\hline Loteria & Independiente & Mañana/tarde & $\begin{array}{l}\text { Masculino/fe } \\
\text { menino }\end{array}$ & $\begin{array}{l}\text { Móvil/Esta } \\
\text { cionario }\end{array}$ & $\begin{array}{l}\text { Estera con los } \\
\text { boletos/exhibi } \\
\text { dor, butaco }\end{array}$ & $\begin{array}{l}\text { Exhibidor/pr } \\
\text { egoneo }\end{array}$ & $\begin{array}{l}\text { Por las } \\
\text { calles, o } \\
\text { lugares } \\
\text { con flujo } \\
\text { masivo de } \\
\text { personas }\end{array}$ \\
\hline $\begin{array}{l}\text { Velas } \\
\text { aromáticas }\end{array}$ & Independiente & Mañana/tarde & $\begin{array}{l}\text { Femenino/M } \\
\text { asculino }\end{array}$ & Móvil & $\begin{array}{l}\text { Maletin con la } \\
\text { mercancía }\end{array}$ & Pregoneo & $\begin{array}{l}\text { Por las } \\
\text { calles, } \\
\text { sector } \\
\text { céntrico, } \\
\text { periferia }\end{array}$ \\
\hline Masas de & Independiente & Mañana/tarde & Masculino & Móvil & Canastilla, & Pregoneo & Por las \\
\hline
\end{tabular}




\begin{tabular}{|c|c|c|c|c|c|c|c|}
\hline $\begin{array}{l}\text { choclo, } \\
\text { envueltos de } \\
\text { maíz }\end{array}$ & $\begin{array}{l}\text { /personal } \\
\text { contratado } \\
\text { informalmente }\end{array}$ & & & & $\begin{array}{l}\text { caja de icopor } \\
\text { con el } \\
\text { comestible }\end{array}$ & & $\begin{array}{l}\text { calles } \\
\text { principalm } \\
\text { ente }\end{array}$ \\
\hline $\begin{array}{l}\text { Periódico, } \\
\text { diarios, } \\
\text { magazines, } \\
\text { informativos } \\
\text { tipo extra }\end{array}$ & $\begin{array}{l}\text { Personal } \\
\text { contratado }\end{array}$ & Mañana/Tarde & $\begin{array}{l}\text { Femenino/M } \\
\text { asculino }\end{array}$ & $\begin{array}{l}\text { Móvil/estac } \\
\text { ionario }\end{array}$ & $\begin{array}{l}\text { Exhibidor, } \\
\text { quiosco, } \\
\text { bicicleta, } \\
\text { triciclo }\end{array}$ & $\begin{array}{l}\text { Pregoneo, o } \\
\text { avisos }\end{array}$ & $\begin{array}{l}\text { Semáforos } \\
\text {, barrios, } \\
\text { periferia }\end{array}$ \\
\hline $\begin{array}{l}\text { Zapatería, } \\
\text { correas, } \\
\text { billeteras, } \\
\text { marroquinerí } \\
\text { a }\end{array}$ & Independiente & Mañana/tarde & $\begin{array}{l}\text { Femenino/m } \\
\text { asculino }\end{array}$ & $\begin{array}{l}\text { Móvil/estac } \\
\text { ionario }\end{array}$ & $\begin{array}{l}\text { Exhibidor, } \\
\text { maletín con } \\
\text { mercancía }\end{array}$ & Pregoneo & $\begin{array}{l}\text { Por los } \\
\text { barrios, } \\
\text { sector } \\
\text { céntrico }\end{array}$ \\
\hline Flores & $\begin{array}{l}\text { Personal } \\
\text { contratado } \\
\text { informalmente }\end{array}$ & Mañana/tarde & $\begin{array}{l}\text { Femenino/M } \\
\text { asculin }\end{array}$ & $\begin{array}{l}\text { Estacionari } \\
0\end{array}$ & $\begin{array}{l}\text { Balde, } \\
\text { exhibidor, } \\
\text { recipientes }\end{array}$ & Pregoneo & $\begin{array}{l}\text { Semáforos } \\
\text {, esquinas } \\
\text { céntricas }\end{array}$ \\
\hline $\begin{array}{l}\text { Camisetas } \\
\text { de equipos } \\
\text { de futbol, } \\
\text { banderas, } \\
\text { artículos } \\
\text { emblemático }\end{array}$ & $\begin{array}{l}\text { Personal } \\
\text { contratado } \\
\text { informalmente } \\
\text { /Independient } \\
\text { e }\end{array}$ & Mañana/tarde & Masculino & $\begin{array}{l}\text { Estacionari } \\
0\end{array}$ & $\begin{array}{l}\text { Cuerda } \\
\text { exhibidora, } \\
\text { butacos }\end{array}$ & $\begin{array}{l}\text { Pregoneo, } \\
\text { visualización }\end{array}$ & $\begin{array}{l}\text { Esquinas, } \\
\text { sitios } \\
\text { estratégico } \\
\mathrm{s}\end{array}$ \\
\hline $\begin{array}{l}\text { S } \\
\text { Cholados }\end{array}$ & Independiente & Mañana/tarde & Masculino & $\begin{array}{l}\text { Movil/estac } \\
\text { ionario }\end{array}$ & $\begin{array}{l}\text { Carrito } \\
\text { exhibidor/tricic } \\
\text { lo, moto }\end{array}$ & $\begin{array}{l}\text { Pregoneo, } \\
\text { aviso }\end{array}$ & $\begin{array}{l}\text { Barrios, } \\
\text { puntos de } \\
\text { sudor, } \\
\text { zona } \\
\text { céntrica, } \\
\text { salida de } \\
\text { escenarios } \\
\text { deportivos, } \\
\text { colegios }\end{array}$ \\
\hline $\begin{array}{l}\text { Mango } \\
\text { tomi/frutas } \\
\text { exóticas, } \\
\text { aguacates }\end{array}$ & $\begin{array}{l}\text { Independiente } \\
\text { /Personal } \\
\text { contratado } \\
\text { informalmente }\end{array}$ & Mañana/Tarde & $\begin{array}{l}\text { Masculino/F } \\
\text { emenino }\end{array}$ & $\begin{array}{l}\text { Estacionari } \\
0\end{array}$ & $\begin{array}{l}\text { Carretilla } \\
\text { exhibidora }\end{array}$ & $\begin{array}{l}\text { Visualizació } \\
\mathrm{n} \text {, pregoneo }\end{array}$ & $\begin{array}{l}\text { Zona } \\
\text { céntrica, } \\
\text { puntos } \\
\text { estratégico }\end{array}$ \\
\hline $\begin{array}{l}\text { Elementos } \\
\text { educativos } \\
\text { (kits } \\
\text { académicos, } \\
\text { sopas de } \\
\text { letras, } \\
\text { recetarios) }\end{array}$ & $\begin{array}{l}\text { Personal } \\
\text { contratado } \\
\text { informalmente }\end{array}$ & Mañana/tarde & $\begin{array}{l}\text { Masculino/F } \\
\text { emenino }\end{array}$ & Móvil & $\begin{array}{l}\text { Maletín con } \\
\text { mercancía }\end{array}$ & Pregoneo & $\begin{array}{l}\text { S } \\
\text { Por los } \\
\text { barrios, } \\
\text { preferiblem } \\
\text { ente }\end{array}$ \\
\hline $\begin{array}{l}\text { Escobas, } \\
\text { traperos, } \\
\text { elementos } \\
\text { de aseo, } \\
\text { cacharro }\end{array}$ & $\begin{array}{l}\text { Personal } \\
\text { contratado } \\
\text { informalmente }\end{array}$ & Mañana/tarde & $\begin{array}{l}\text { Masculino/F } \\
\text { emenino }\end{array}$ & Móvil & $\begin{array}{l}\text { Mercancía en } \\
\text { carretillas, o } \\
\text { cargada } \\
\text { manualmente }\end{array}$ & Pregoneo & $\begin{array}{l}\text { Por los } \\
\text { barrios, } \\
\text { preferiblem } \\
\text { ente }\end{array}$ \\
\hline Ensaladas & Independiente & $\begin{array}{l}\text { Mañana/medi } \\
\text { odía }\end{array}$ & Femenino & $\begin{array}{l}\text { Estacionari } \\
0\end{array}$ & $\begin{array}{l}\text { Exhibidor, } \\
\text { recipientes } \\
\text { plásticos, } \\
\text { mesa }\end{array}$ & $\begin{array}{l}\text { Aviso, } \\
\text { visualización }\end{array}$ & $\begin{array}{l}\text { Esquinas } \\
\text { de los } \\
\text { barrios, } \\
\text { andenes } \\
\text { de las }\end{array}$ \\
\hline $\begin{array}{l}\text { Presas de } \\
\text { pollo }\end{array}$ & Independiente & $\begin{array}{l}\text { Mediodía/tard } \\
\text { e }\end{array}$ & Femenino & $\begin{array}{l}\text { Estacionari } \\
\text { o }\end{array}$ & $\begin{array}{l}\text { Exhibidor, } \\
\text { vitrina, mesas, } \\
\text { asientos } \\
\text { plásticos }\end{array}$ & $\begin{array}{l}\text { Aviso, } \\
\text { visualización }\end{array}$ & $\begin{array}{l}\text { casas } \\
\text { Esquinas, } \\
\text { sitios } \\
\text { estratégico } \\
\text { s de la } \\
\text { ciudad }\end{array}$ \\
\hline Fritanga & Independiente & Tarde/Noche & Femenino & $\begin{array}{l}\text { Estacionari } \\
0\end{array}$ & $\begin{array}{l}\text { Vitrina, } \\
\text { exhibidor, }\end{array}$ & $\begin{array}{l}\text { Visualizació } \\
\text { n, }\end{array}$ & $\begin{array}{l}\text { Esquinas } \\
\text { de barrios }\end{array}$ \\
\hline
\end{tabular}




\begin{tabular}{|c|c|c|c|c|c|c|c|}
\hline \multirow[b]{2}{*}{$\begin{array}{l}\text { Arepas/chori } \\
\text { zos/chuzos }\end{array}$} & \multirow[b]{2}{*}{ Independiente } & \multirow[b]{2}{*}{$\begin{array}{l}\text { Mañana/tarde/ } \\
\text { noche }\end{array}$} & \multirow[b]{2}{*}{ Femenino } & \multirow[b]{2}{*}{$\begin{array}{l}\text { Estacionari } \\
\text { o }\end{array}$} & \multicolumn{2}{|l|}{ mesas, sillas } & \multirow{2}{*}{$\begin{array}{l}\text { principalm } \\
\text { ente } \\
\text { Esquinas } \\
\text { de barrios, } \\
\text { sitios } \\
\text { estratégico } \\
\text { s }\end{array}$} \\
\hline & & & & & $\begin{array}{l}\text { Parrilla, } \\
\text { exhibidor, } \\
\text { mesa, asador, } \\
\text { asientos }\end{array}$ & $\begin{array}{l}\text { Visualizació } \\
\text { n }\end{array}$ & \\
\hline $\begin{array}{l}\text { Muebles/esp } \\
\text { ejos/consola } \\
\text { s/cómodas/c } \\
\text { amas }\end{array}$ & $\begin{array}{l}\text { Personal } \\
\text { contratado }\end{array}$ & Mañana/tarde & Masculino & $\begin{array}{l}\text { Móvil/estac } \\
\text { ionario }\end{array}$ & $\begin{array}{l}\text { Carretilla, } \\
\text { vehiculo } \\
\text { exhibidor }\end{array}$ & Pregoneo & $\begin{array}{l}\text { Barrios, } \\
\text { esquinas, } \\
\text { estratégica } \\
\text { s }\end{array}$ \\
\hline $\begin{array}{l}\text { Jugos, } \\
\text { refrescos, } \\
\text { bolis, sandis, } \\
\text { gaseosas, } \\
\text { energizantes }\end{array}$ & $\begin{array}{l}\text { Personal } \\
\text { contratado }\end{array}$ & Mañana/tarde & Masculino & $\begin{array}{l}\text { Móvil/estac } \\
\text { ionario }\end{array}$ & $\begin{array}{l}\text { Cajonero } \\
\text { exhibidor, caja } \\
\text { de icopor con } \\
\text { emblemas }\end{array}$ & $\begin{array}{l}\text { Pregoneo } \\
\text { /uniforrme } \\
\text { promocional }\end{array}$ & $\begin{array}{l}\text { Esquinas/s } \\
\text { emáforos, } \\
\text { sitios } \\
\text { estratégico } \\
\mathrm{s}\end{array}$ \\
\hline $\begin{array}{l}\text { Artículos de } \\
\text { hogar } \\
\text { (edredones, } \\
\text { cubiertas, } \\
\text { cortinas) }\end{array}$ & $\begin{array}{l}\text { Personal } \\
\text { contratado }\end{array}$ & Mañana/tarde & $\begin{array}{l}\text { Masculino/F } \\
\text { emenino }\end{array}$ & Móvil & $\begin{array}{l}\text { Maletin con } \\
\text { mercancía }\end{array}$ & $\begin{array}{l}\text { Pregoneo/pu } \\
\text { erta a puerta }\end{array}$ & $\begin{array}{l}\text { Por los } \\
\text { barrios }\end{array}$ \\
\hline $\begin{array}{l}\text { Artículos } \\
\text { estacionales } \\
\text { (elementos } \\
\text { decorativos } \\
\text { navideños, } \\
\text { arreglos } \\
\text { florales amor } \\
\text { y amistad, } \\
\text { dia de la } \\
\text { madre, } \\
\text { sahumerios, } \\
\text { velitas } \\
\text { romanas, } \\
\text { etc) }\end{array}$ & $\begin{array}{l}\text { Personal } \\
\text { contratado } \\
\text { informalmente }\end{array}$ & Mañana/tarde & $\begin{array}{l}\text { Masculino/F } \\
\text { emenino }\end{array}$ & $\begin{array}{l}\text { Móvil/Esta } \\
\text { cionario }\end{array}$ & $\begin{array}{l}\text { Exhibidores, } \\
\text { maletines con } \\
\text { mercancía }\end{array}$ & $\begin{array}{l}\text { Pregoneo, } \\
\text { visualización }\end{array}$ & $\begin{array}{l}\text { Esquinas, } \\
\text { sitios } \\
\text { estratégico } \\
\mathrm{s}\end{array}$ \\
\hline Gafas & Independiente & Mañana/tarde & $\begin{array}{l}\text { Masculino/F } \\
\text { emenino }\end{array}$ & $\begin{array}{l}\text { Estacionari } \\
0\end{array}$ & $\begin{array}{l}\text { Exhibidores, } \\
\text { espejos, } \\
\text { mesón }\end{array}$ & $\begin{array}{l}\text { Pregoneo, } \\
\text { visualización }\end{array}$ & $\begin{array}{l}\text { Sitios } \\
\text { estratégico } \\
\text { s del } \\
\text { centro de } \\
\text { la ciudad }\end{array}$ \\
\hline
\end{tabular}

\section{Análisis y discusión del objeto de estudio}

Para abordar esta fase, se procedió a utilizar técnicas cualitativas como la entrevistas a diferentes representantes de los grupos de interés, y encuestas personalizadas con esta comunidad, para cotejar y discutir las diferentes posiciones y puntos de vista.

\section{Encuestas relacionadas (69)}

\section{Género del vendedor}




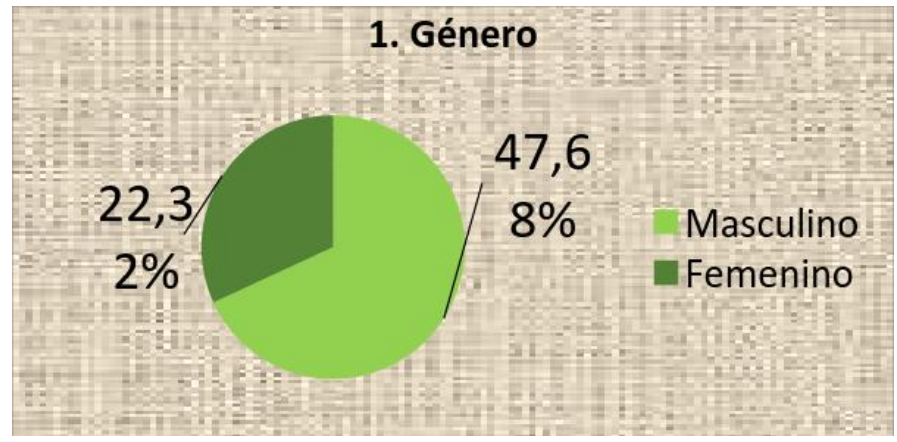

Interpretación: Las actividades comerciales de índole informal, por lo regular las realizan hombres.

2. Estrato socioeconómico donde vive:

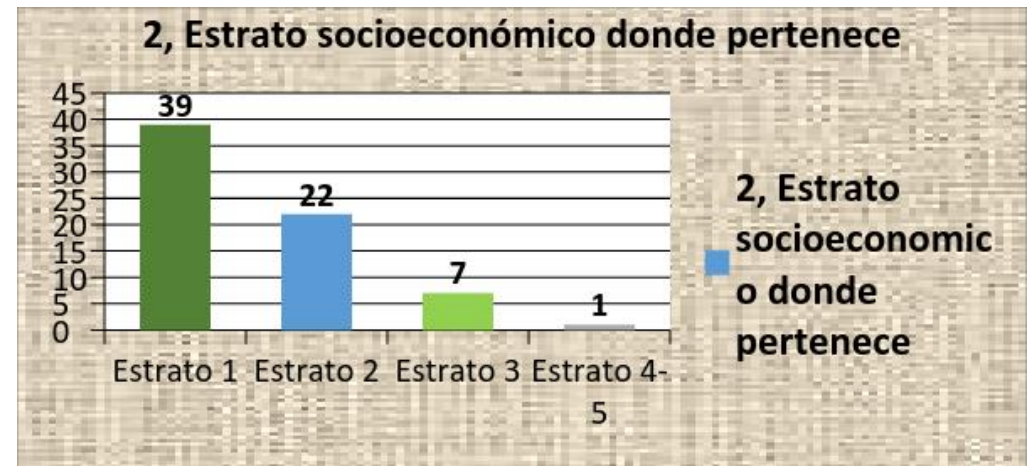

Interpretación. 56,52\% corresponde al estrato socioeconómico más bajo, seguido por un $31.88 \%$ de estrato 2 que se considera de clases menos desfavorecidas. Estas cifras dan por sentado que los vendedores ambulantes proceden de barrios bajos.

\section{Tipo de mercancía ofrecida por estos vendedores}

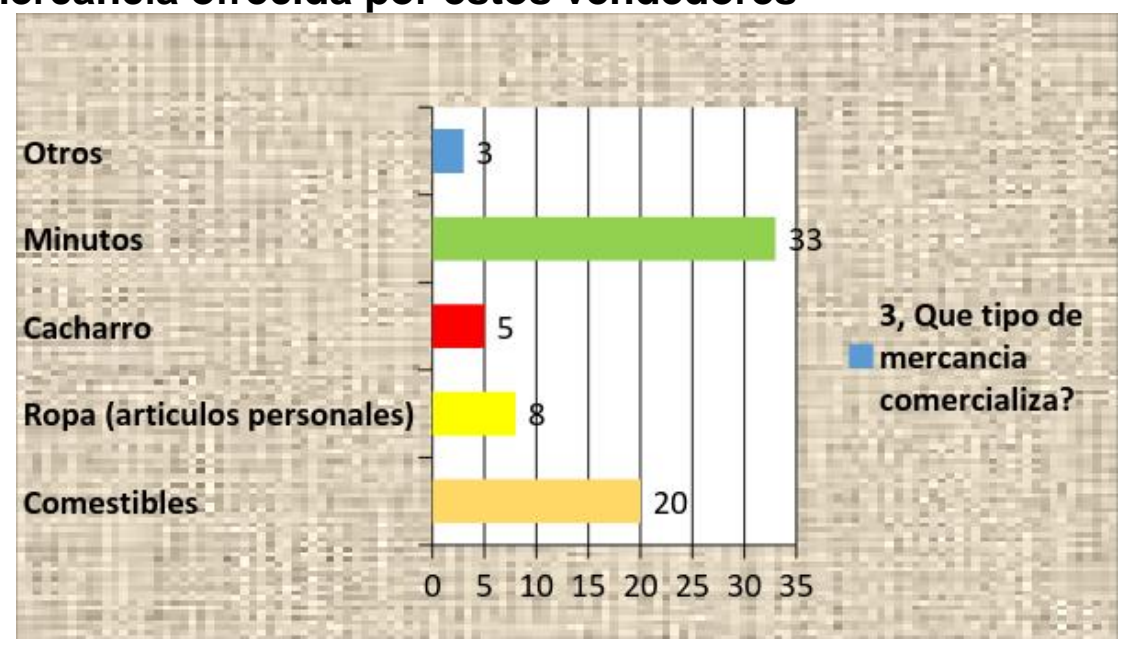

Interpretación: La venta de minutos con un $47.82 \%$ constituye la practica más común de comercialización, seguida por un $29 \%$ de ventas de comidas, aprovechando la aceptación cultural de comer por fuera del palmirano. 
4. Escogencia de este tipo de trabajo

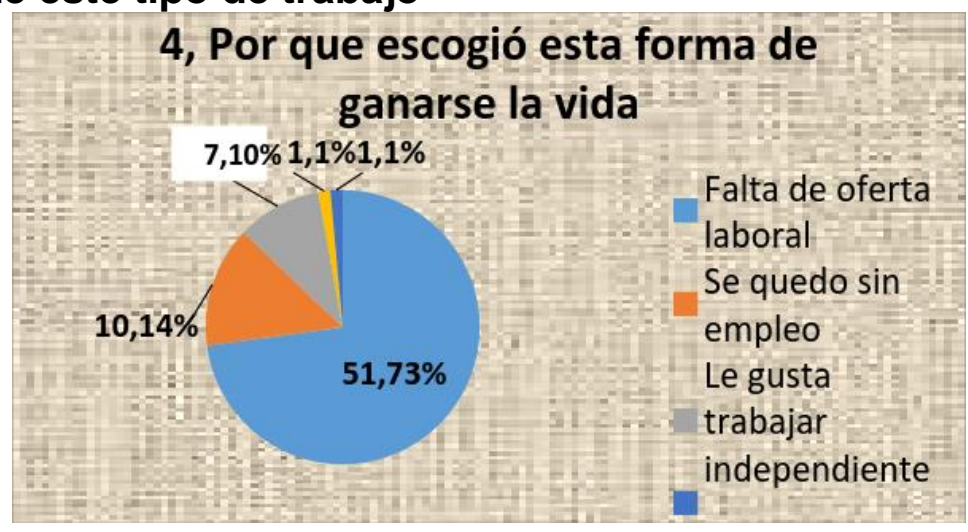

Interpretación: $73 \%$ es un valor contundente, que pone de manifiesto que muchos de estos vendedores laboran de esta manera, al adolecer de una oferta laboral seria.

\section{Ingresos promedio por la actividad diaria}

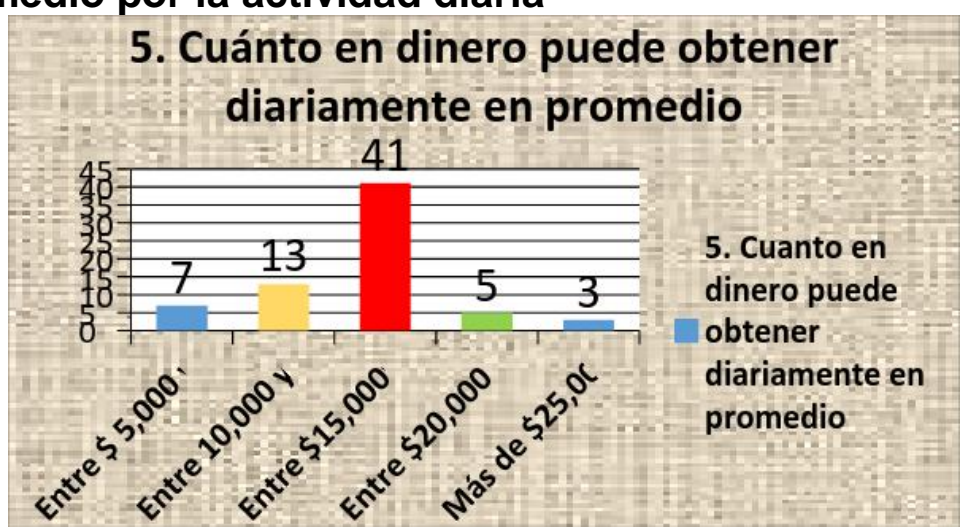

Interpretación: $78.26 \%$ si suman los rangos entre 10.000 y 15.000 y 15.000 y 20.000 respectivamente, es un indicio que el negocio es rentable por lo bajo, en un rango de uno y dos salarios mínimos, es decir es claro, que nadie consigue un gran capital como vendedor ambulante.

6. Horas empleadas para llevar a cabo la jornada laboral

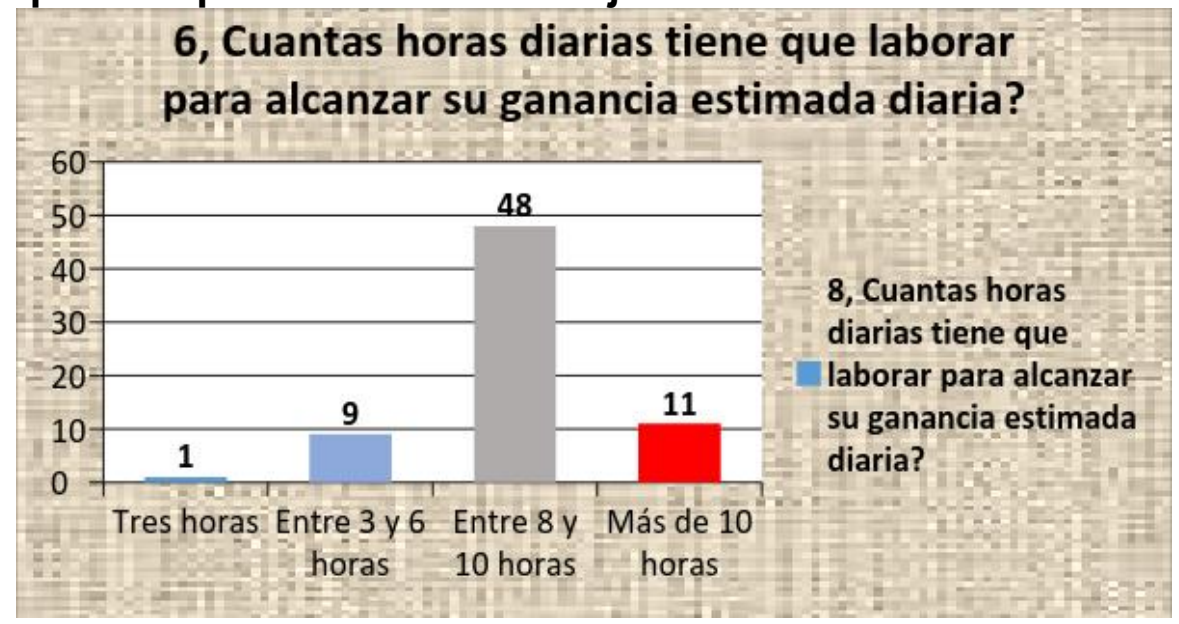


Interpretación: $69.56 \%$ es un valor muy significativo, lo que indica que una persona tendrá necesariamente que ocuparse más de la jornada laboral recomendada por el Gobierno. Incluso llama la atención, el casi $16 \%$ de los encuestados que superan este lapso de tiempo.

\section{Factor crítico de éxito}

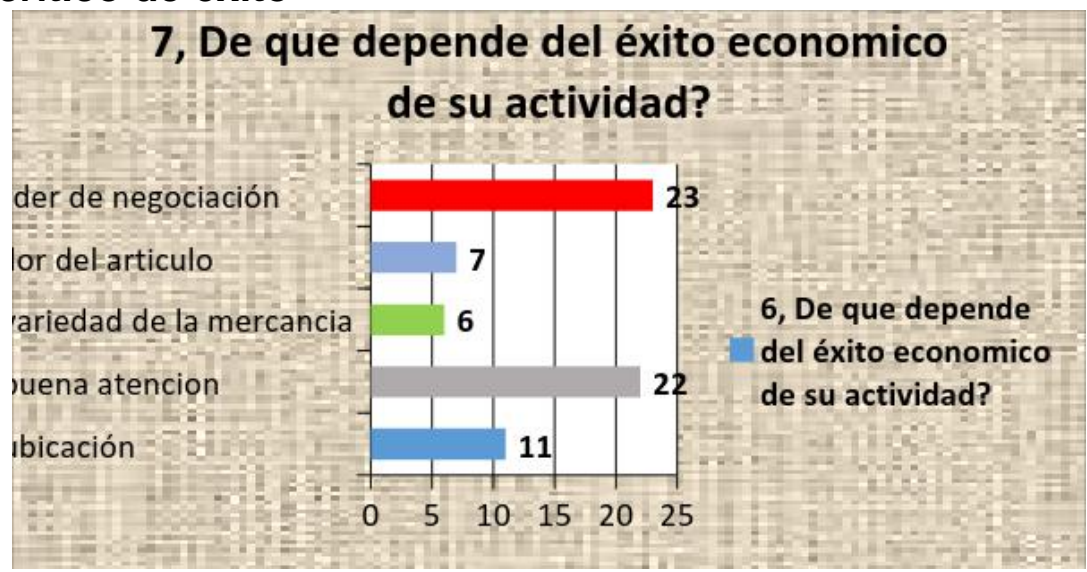

Interpretación: $33.33 \%$ y $31.88 \%$ respectivamente, ponen de manifiesto que la buena atención y el poder de negociación son claves para ser exitosos con esta actividad. De hecho, se dice que los vendedores tienen mucha "labia" para convencer a sus clientes.

\section{Riesgos asociados a la actividad}

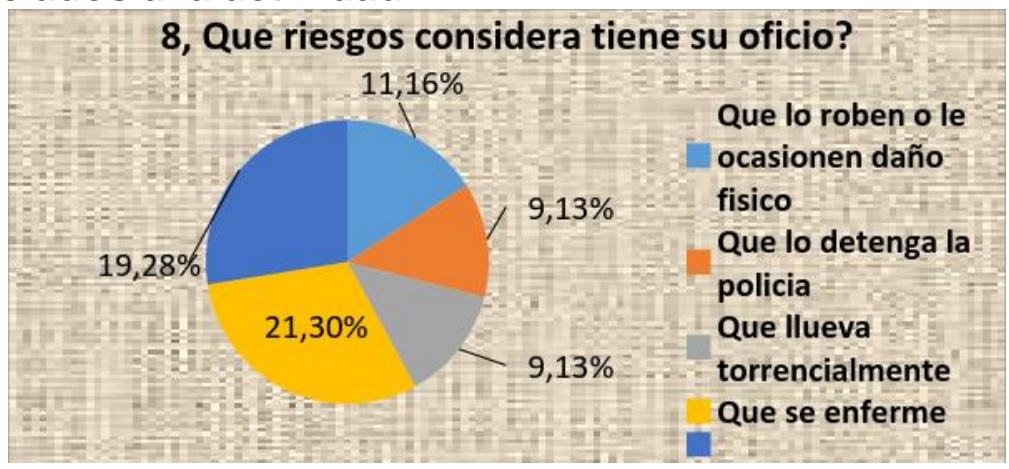

Interpretación: las calificaciones estuvieron muy equilibradas, sin embargo, existen dos factores fundamentales, (30\%, y $28 \%$ ) que ellos no se enfermen, pues dependen de su concurso diario para obtener su sustento, y que la mercancía no falte, porque ellos prácticamente dependen de sus proveedores.

\section{Nivel de percepción sobre la afectación de su labor}




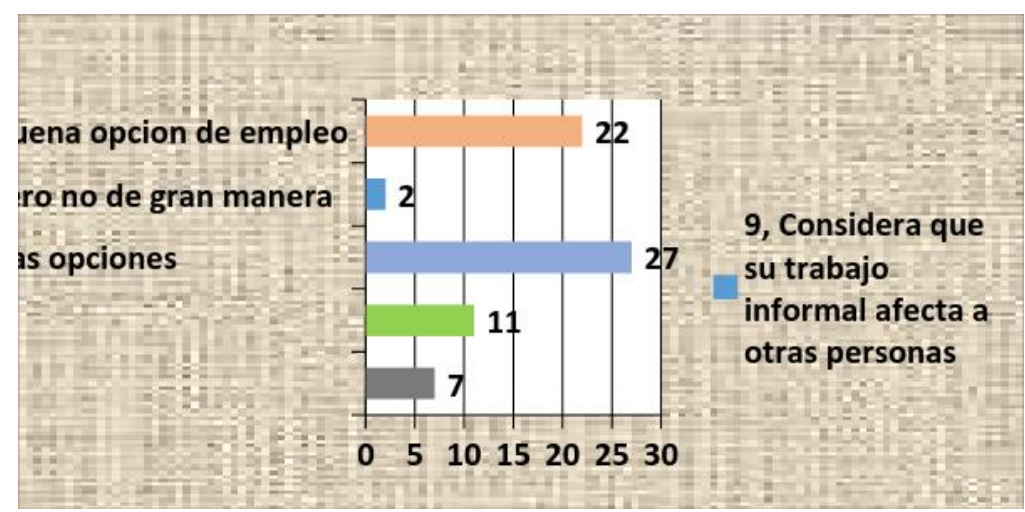

Interpretación: Resulta llamativo que tres de las respuestas afirmativas, fueron contestadas, con un poco más del $50 \%$, lo que infiere que esta comunidad es consciente de que sus labores son ilícitas pero las ven como algo imposible de erradicar.

10.Posición de acuerdo /desacuerdo reubicación espacial

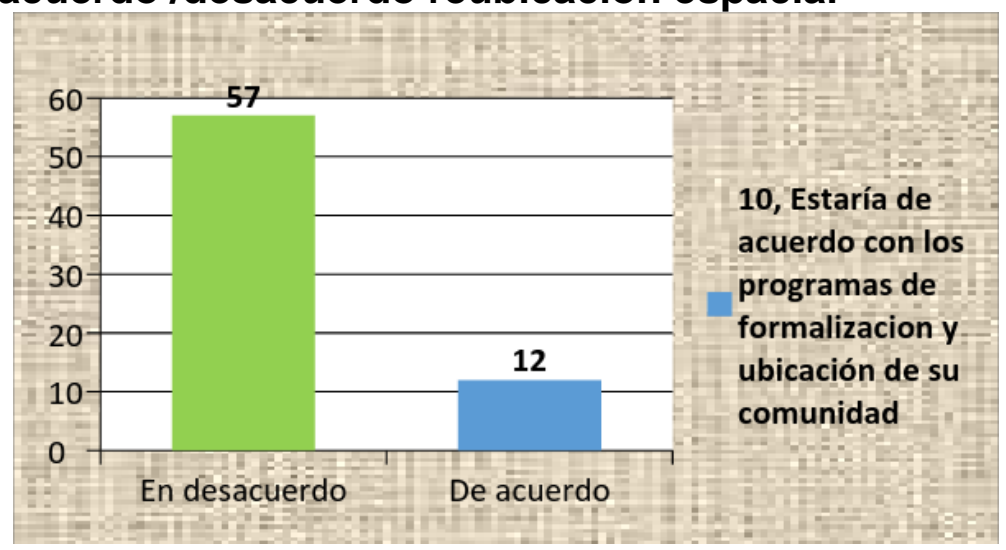

Interpretación: En forma contundente, los vendedores ambulantes muestran sus voces opositoras ante la posibilidad de una potencial reubicación.(82.60\%)

\section{Entrevistas a grupos de interés}

\section{Entrevistado 1: Hugo González Vélez (Propietario Almacén Calzado)}

Autor monografía: Cordial saludo, quería preguntarle, qué opinión le merecen los vendedores ambulantes y los vendedores estacionarios en general?

Entrevistado: Un saludo para usted también...pues que le digo, este gremio ha cogido mucha fuerza en la ciudad, y pues la verdad nosotros los comerciantes nos hemos visto afectados la verdad...en mi caso, yo antes me vendía 12 a 15 millones en mercancía, hoy en dia no llego ni a 8 millones, y eso que con miles de maromas.

Autor monografía: Mucha gente respecto al tema, opina que es un problema difícil de solucionar, que opina usted?

Entrevistado: Estoy convencido de lo que se dice, porque como le comentaba antes, esta gente ha cogido mucha fuerza, es increíble, por donde queda el almacena, hay más de 15 puestos diferentes, el aviso del almacén, escasamente se ve...yo al principio 
los espantaba porque me daba piedra...pero ya uno aprende a convivir con esta comunidad.

Autor monografía: En determinado momento, cree que los transeúntes, la gente del común, se siente beneficiada con la oferta laboral de esta comunidad?

Entrevistado: Pues, me inclino por pensar lo mismo, por ejemplo, yo empecé como vendedor ambulante, y uno le va cogiendo cariño al oficio, y a la gente que le compra, sino que no deja de ser un problema, y en cuanto a la oferta, pues si, algunas cosas que ellos venden, sobre todo los comestibles, facilitan la compra de ello, yo soy único que colaboro con la compra de chicles, jugos, chontaduros, churros, etc. Digamos que uno termina haciendo amigo de todo mundo, por mutua conveniencia.

\section{Autor monografía: Qué opinión le merece los proyectos de reubicar a esta comunidad?}

Entrevistado: Pues ya unos de ellos, que los ubicaron en un parqueadero, pero eso no función, porque la gente como sea va a tratar de volverse al lugar donde estaban, porque ellos tienen ya su clientela, y no van a dar el brazo a torcer tan fácilmente, en Cali, por el centro, ellos tienen "campaneros" que les avisan cuando las autoridades están por ahí pendientes para confiscarles su mercancía.

Autor monografía; Desde su perspectiva, que factores han contribuido a que esta población de vendedores informales haya ganado en presencia en la zona céntrica de la ciudad?

Entrevistado: Factores, pues haber...yo pienso que la falta de trabajo, uno como comerciante no le alcanza el presupuesto para contratar personal, no hay empleo para ofrecer, otro factor, la falta de cumplimiento de las normas, de ley...los policías se dejan sobornar, uno los ve incluso comprando películas, música o ropa, a sabiendas que esta gente no paga impuesto.

Autor monografía: Por último, que solución le ve, o sugiere para el manejo de esta comunidad?

Entrevistado: Pues la verdad, sería bueno que ellos todos, no algunos sino todos, tuvieran su carnet, y que se les cobrara un impuesto así sea el mínimo, para que pueda haber una competencia equilibrada. Que así venda chicles, o fritanga se les cobre algo, que no se la ganen tan fácil.

\section{Entrevistado 2: Andrés Hernández (Gestor Bancario BBVA)}

Autor monografía: Cordial saludo, quería preguntarle, qué opinión le merecen los vendedores ambulantes y los vendedores estacionarios en general?

Entrevistado: Buenos días, pues son personas que trabajan, pero que lo hacen, de acuerdo a sus posibilidades, pienso que hacen parte de la cultura propia de cada ciudad, al menos aquí en Palmira, hay cientos de ellos, pero pienso que son personas de bien, gente echada pal ante como se dice...

Autor monografía: Mucha gente respecto al tema, opina que es un problema difícil de solucionar, que opina usted? 
Entrevistado: Si admito que es un problema, porque de todas formas ellos no pagan impuestos, por ese lado, y por otro lado pues entiendo que algo se han intentado, particularmente pienso es que deben organizarlos mejor, porque en el caso mío, yo tengo un carro, y ríase el problema para andar por el centro...es que no se puede, además que algunos se enojan, cuando uno les dice algo. Yo diría...que es un problema no tan serio, pero si presentan molestias sobre todo en el centro de la ciudad.

Autor monografía: En determinado momento, cree que los transeúntes, la gente del común, se siente beneficiada con la oferta laboral de esta comunidad?

Entrevistado: Difícil contestar eso, porque uno mismo si necesita comprar películas o música así de afán, por ejemplo, en navidad alguna musiquita para escuchar...villancicos etc, pues esta gente la vende y no toda es mala, o también venden correas, en el caso mío yo compro corbatas a un muchacho que las vende bonitas por ahí por el Nadia. Por otro lado existe mucho vendedor que comercializa productos "chiviados", entonces como que por ahí no es la cosa....

\section{Autor monografía: Qué opinión le merece los proyectos de reubicar a esta comunidad?}

Entrevistado: El otro día fui a guardar el carro, cerca al Bancolombia de la 30 con 26, y me toco devolverme pues habían un poco de vendedores que los habían ubicado allí, me dio hasta pesar, porque yo se que ellos también necesitan su espacio para ejercer sus labores. He escuchado que el actual alcalde tiene un proyecto de crearles una especie de parque exclusivo para ellos, sería bueno, habría que esperar.

\section{Autor monografía; Desde su perspectiva, que factores han contribuido a que esta población de vendedores informales haya ganado en presencia en la zona céntrica de la ciudad?}

Entrevistado: Que le pudiera decir, yo pienso que acá en Palmira, no sobreabundan los empleos, existe muchos negocios propios, pero pequeños, no da margen para que se contrate mucho personal, por otro lado, pienso que la gente también le gusta ganársela de esta manera, yo he visto y conozco gente que le gusta esta actividad, y aun sabiendo que es ilegal, lo hacen sin ningún temor.

Autor monografía: Por último, que solución le ve, o sugiere para el manejo de esta comunidad?

Entrevistado: La solución es que los organicen, que ellos tengan chance de trabajar agremiadamente, pues no me imagino Palmira sin vendedores ambulantes, de todas formas hacen falta.

\section{Resultados y discusión}

Los vendedores ambulantes constituyen más perjuicios que beneficios en un municipio como el de Palmira, puesto que sobreabunda este tipo de comerciantes informales, y están demasiado organizados, de hecho ya un proyecto de la Alcaldía 
aprobado para reubicar esta comunidad en un solo tipo para el año 2016. No obstante, hay que decir a favor de este gremio, es que legítimamente ellos tienen derecho a laborar, porque este tipo de comercialización directa, no es tipificado como delito ante la jurisdicción colombiana; el asunto que si crea una discusión desde el ámbito del derecho, es que debe primar el derecho al trabajo, o el derecho a la vía publica.

\section{Conclusiones}

Los factores que han incidido en forma progresiva y contundente en la consolidación de la economía informal (vendedores ambulantes y vendedores estacionarios) han sido en su orden; la falta de oferta laboral de las entidades públicas y privadas, la indiferencias de las autoridades, de la gente del común, y la misma cultura del palmirano de ser solidario con este tipo de actividades.

El género masculino, sobrepasa con creces a los ofertantes de este tipo de actividad comercial, y aunque hay ventas de todo (en la calle encuentra desde una aguja, hasta un casco para motos), lo que más ha ganado fuerza son las ventas de minutos, la venta de cascos, y la venta de presas de pollo.

Los vendedores ambulantes sobreabundan a pesar de los números y potenciales peligros que encuentran en la calle, no obstante, ellos mismos manifiestan que lo peor que les puede pasar es que se enfermen, que llueva en forma torrencial, o que la mercancía se escasee,

No constituye una problemática, ni la gente como tal ve no percibe esta comunidad como un flagelo, reconocen que sus prácticas no son del todo legales, pero que de alguna manera aportan a la sociedad, con ofertas de productos útiles, y económicos.

Se recomienda que al tenor de la realidad que vivencia en su dia a dia, esta comunidad que se les ofrezcan alternativas viables y que redunden en su beneficio, y no utilizar las medidas drásticas que en ocasiones toman para su erradicación.

Se sugiere de igual forma, que exista una política que propenda por agremiar esta comunidad y no dispersarla, pues finalmente, algunas empresas también se ven beneficiadas por los productos que ellos comercializan.

\section{Literatura citada}

Abad, D. (1997). Acción de marketing. Colombia: Interpared Editores.

Fishkin, R., \& Hogenhaven, T. (2013). Inbound marketing and SEO: Insights from the Moz Blog. Wiley.

Goffman, E. (1970). Ritual de la interacción. Tiempo contemporáneo, 37.

Hymes, D. (1972). "Models of interaction of language and social life". en Gumperz, John y Dell Hymes (compiladores). Holt, Rinehart y Wilston. Nueva York. 
Posada, A., Dávila Rincón, J., \& Castro Estrada, V. (2008). Perfil psicográfico de los compradores de venta directa por catálogo en Manizales. Manizales: Universidad de Manizales.

Reid, A. (1990). Venta moderna aplicada. Nueva York: Prentice-Hall.

Saville-Troike, M. (2005). La etnografía de la comunicación: una introducción. Buenos Aires: Prometeo.

Serna, H. (2000). Gerencia Estratégica. Caracas: Ediciones Global S.A.

Simpson, P., \& Jevons, C. (2009). Internet-enabled International Marketing: A Small Business.

Stanton, W., Etzel, M., \& Walker, B. (2004). Fundamentos de Marketing. México: McGraw-Hill Interamericana,.

Vargas, S. (2014). Por qué debe implementar una estrategia de inbound marketing si quiere crecer sus ventas. Bogotá: Giraffe.

Veleda da Silva, S. (2003). Trabajo informal, género y cultura: el comercio callejero e informal en el sur de Brasil. . Barcelona: Universidad Autónoma de Barcelona.

Werther, W., \& Keith, D. (2000). Administración de Personal y Recursos Humanos. México: McGraw Hill Interamericana. Complementaria.

Wilcok, M. (2011). Marketing de Contenidos. Crear para convertir. España. 